\title{
Havran Baraj Gölüne Dökülen Yüzeysel Akışın SWMM ile Tahmini*
}

\author{
Kağan Cebe ${ }^{1 * *}$, Asu İnan ${ }^{2}$ \\ ${ }^{1}$ Nevşehir Hacı Bektaş Veli Üniversitesi, Mühendislik Mimarlık Fakültesi, İnşaat Mühendisliği Bölümü, Nevşehir, Türkiye (ORCID: 0000-0003-1288-1362) \\ ${ }^{2}$ Gazi Üniversitesi, Mühendislik Fakültesi, İnşaat Mühendisliği Bölümü, Ankara, Türkiye (ORCID: ORCID: 0000-0003-2569-2456)
}

(Konferans Tarihi: 5-7 Mart 2020)

(DOI: 10.31590/ejosat.araconf20)

ATIF/REFERENCE: Cebe, K. \& İnan, A. (2020). Havran Baraj Gölüne Dökülen Yüzeysel Akışın SWMM ile Tahmini. Avrupa Bilim ve Teknoloji Dergisi, (Özel Sayı), 152-160.

\begin{abstract}
$\ddot{O} \mathbf{z}$
Yağışlardan dolayı meydana gelen yüzeysel akışın tahmin edilmesi, su kaynaklarıyla ilgili çalışmaların temelidir. Bu sebeple, yağış akışs sürecinin benzetimi amacıyla MIKE, BASIN ve SWMM gibi modeller geliştirilmiş̧ir. Yağış türü, miktarı, süresi, sıcaklık, nem ve rüzgâr gibi meteorolojik faktörlerin yanında, havzadaki arazi kullanım türleri, toprak yapısı, eğim, drenaj güzergâhı ile havzada bulunan göl, rezervuar ve su yapıları gibi fiziksel faktörler de yüzeysel akışa etki eder. Bu çalışmada, 2002 yılında taşkın koruma amacıyla inşa edilmiş olan Havran barajını besleyen Havran çayının havzası (Balıkesir), sayısal yükseklik haritaları ve coğrafi bilgi sistemleri (CBS) araçları kullanılarak belirlenmiştir. Sayısal yükseklik modelleri (SYM/DEM), arazi şekli ve yükseltileri, akarsu drenajı, deseni ve çizgiselliklerini analiz etmek için kullanılmıştır. Drenaj havzası, fiziksel, hidrolojik ve arazi kullanımı parametrelerine göre bölümlendirilmiştir. Alt havzaların belirlenmesinde arazilerin, yükseklik modelleri ve jeolojik haritaları yanında güncel durumunu gösteren 2018 yılı CORINE sayısal haritaları da kullanılmıştır. Havzayı oluşturan alt bölümler sayısallaştırılarak, topografya akış yönü ve birikiminin tespit edilmesi ile yüzeysel akış miktarları hesaplanmıştır. EPA-SWMM, Amerika Birleşik Devletleri Çevre Koruma Ajansı - Taşkın Yönetim Modeline göre yağış akış sürecinin modeli oluşturulmuştur. Model, alt havzayı uniform eğime sahip, ortalama genişlikte bir arazi olarak varsayarak, yüzeyde oluşan yüzeysel akışın drenaj havzasına aktarıldığı kabulleri ile hesap yapmaktadır. Buna göre yăğı̧ ile gelen su miktarından buharlaşma ve sızma sonucu oluşan kayıplardan sonra kalan miktarı yüzeysel akış eşitliklerinde kullanılmaktadır. Bölgedeki meteoroloji istasyondan elde edilen 5 yıllık veriler ile ortalama günlük yağış miktarları hesaplanmıştır. Sıcaklık, nem, buharlaşma gibi diğer meteorolojik veriler SWMM modelini oluşturmak için kullanılmıştır. Hazırlanan SWMM modeli kullanılarak oluşması muhtemel yüzeysel akış değerleri bu model ile belirlenmiş ve baraja dökülmesi muhtemel mevsimsel yüzeysel akış tahmini yapılmıştır.
\end{abstract}

\section{Estimation of Surface Runoff to Havran Dam Lake by Using SWMM}

\begin{abstract}
Estimating the surface runoff due to precipitation is the basis of studies on water resources. Consequently, researchers have developed models such as MIKE, BASIN and SWMM, to simulate the precipitation and surface flow processes. Besides the meteorological factors such as precipitation type, amount, duration, temperature, humidity and wind, physical factors such as land use types, soil structure, drainage route and its slopes, lakes, reservoirs and the water structures in the basin also affect the surface flow. In this study,
\end{abstract}

\footnotetext{
${ }^{*}$ Bu makale International Conference on Access to Recent Advances in Engineering and Digitalization (ARACONF 2020) de sunulmuştur.

** Sorumlu Yazar: Nevşehir Hacı Bektaş Veli Üniversitesi, Mühendislik Mimarlık Fakültesi, İnşaat Mühendisliği Bölümü, Nevşehir, Türkiye, ORCID: 0000-0003-1288-1362, kcebe@ nevsehir.edu.tr
} 
the drainage basin of Havran dam, Balıkesir, which is built in 2002 for the purpose of flood protection, is drawn by using numerical altitude maps and geographic information systems (GIS) tools. The study uses digital elevation models (DEM) to analyze land shapes, elevations, stream patterns and lineaments. It divides the drainage basin into subcatchments according to spatial identifiers such as physical and hydrological data, and by taking into consideration land use parameters. In the determination of the subcatchments, CORINE numerical maps showing the land use status of year 2018 as well as SYM/DEM and geological maps are used. The surface flow rates are calculated via digitizing the topography of the subcatchments, flow direction and flow accumulation. A model of surface flow process is built by using EPA-SWMM, United States Environmental Protection Agency - Storm Water Management Model. The model assumes the subcatchment as a surface with uniform slope and average width. Accordingly, the remaining amount after evaporation and seepage losses from precipitation is the surface flow transferred to the drainage system. By using this model, the seasonal surface flow drained into the lake is simulated according to the rainfall intensity and other meteorological data such as temperature, humidity, evaporation obtained from the regional stations.

Keywords: SWMM, Surface Runoff, GIS, DEM.

\section{Giriş}

Su kütlesini çevreleyen havzadaki arazilerde yağışlar ile birlikte oluşan yüzeysel akışlar yoluyla havzanın bağlı olduğu su kütlelerine ulaşır. Yüzeysel akışı, yağış türü, miktarı, süresi, sıcaklık, nem ve rüzgâr gibi meteorolojik faktörlerin yanında, havzadaki arazi kullanım türleri, toprak yapısı, eğim, drenaj güzergâhı ile havzada bulunan göl, rezervuar ve su yapıları gibi fiziksel faktörler de belirler.

Literatürde ortaya konmuş çok sayıda yağış-taşkın modeli bulunmaktadır. US Soil Conservation Service tarafından geliştirilen SCS (soil complex cover) metodunda yüzeysel akış, taşkın katsayısı olarak tanımlanan bir katsayı yardımı ile hesaplanmaktadır (SCS, 1986; Chen, 1982). HEC, HEC-RAS, HSPF, BASINS, WMS gibi taşkın modellerinde ise yüzeysel akışın drenaj güzergâhının taşkının gecikmesindeki etkisi göz önüne alınmakta, birim hidrograf metodu gibi istatiksel yaklaşımlar kullanılmaktadır (Nelson ve diğ., 1994; USEPA, 2019; Feldman, 1981). SWAT ve SWMM gibi kompleks taşkın modellerinde zamana bağlı olarak hesaplanan yüzeysel akış miktarı yanında arazi kullanımından kaynaklanan ve yüzeysel akışla birlikte taşınan kirletici miktarları da hesaplanabilmektedir (Daniel, 2011).

Havran çayı, Balıkesir ili sınırlarında Kaz dağları'nın güney yamaçları, Madra dağı'nın batı ve kuzey yamaçlarındaki derelerin birleşmesiyle oluşan ve Edremit Körfezi'nden Ege denizine dökülen, yıllık ortalama $86 \mathrm{hm}^{3} / \mathrm{y}$ ll akışa sahip bir akarsudur (BİKTM , 2020; BÇŞİM, 2020). Havran Çay'nın uzunluğu 36 km, vadi uzunluğu 44,5 km, havzasının çevresi 138 km, alanı 570 km²'dir (BİKTM, 2020). Havran çayı üzerinde 1528, 1904, 1958, 1964, 1968, 1980 ve 1981 yıllarında taşkın olayı görülmüştür (Özdemir ve Bird, 2009).

Havran Barajı (Şekil 1), 3.060ha'lık bir alana sulama hizmeti vermek ve taşkından koruma amacı ile inşa edilmiştir. Baraj, Havran çayı üzerinde kurulmuş, kil çekirdekli kaya gövde dolgu tipinde bir barajdır. Barajın inşaatına 1995 yılında başlanmış ve 2010 yılında tamamlanmıştır Barajın, talvegten yüksekliği 64m'dir. Normal su kotunda göl hacmi $66 \mathrm{hm}^{3}$, göl yüzey alanı ise 3,15 km²' dir (BÇŞİM, 2020).

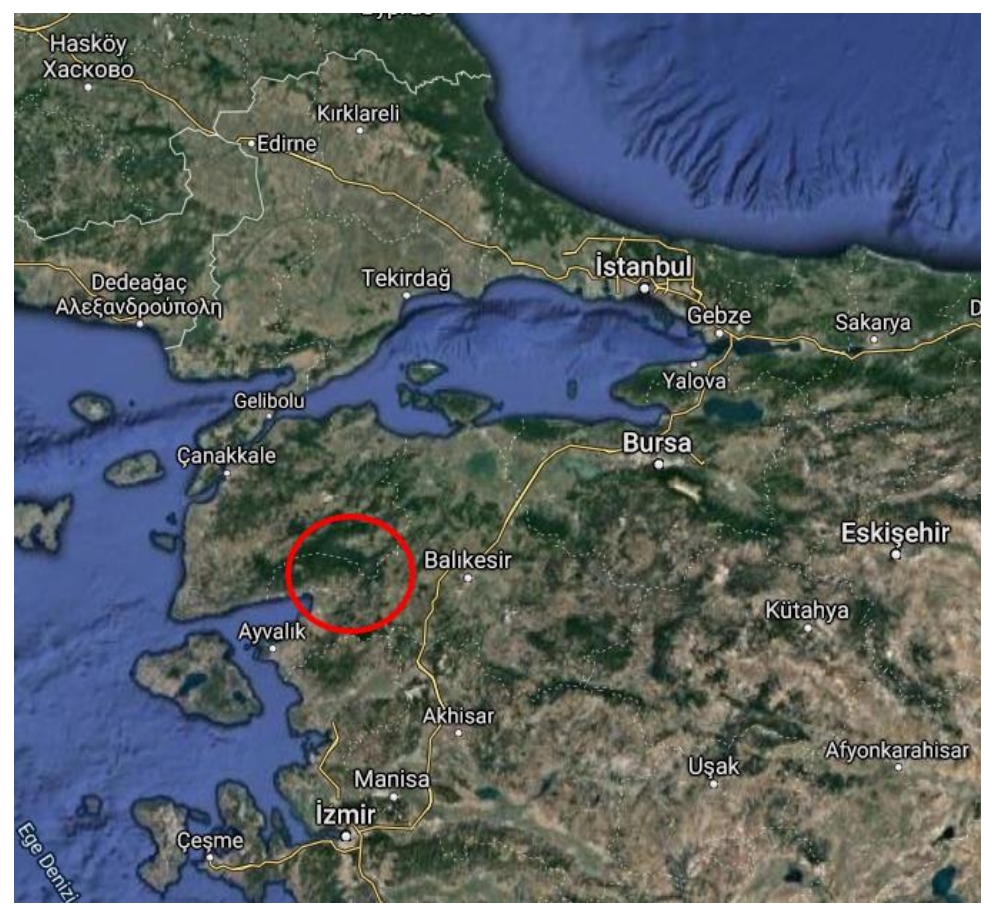

Şekil 1. Havran barajı konumu (Googlemaps, 2020) 


\section{Materyal ve Metot}

\subsection{Havza ve Alt Havzaların Sayısal Haritaları}

Bu çalışma kapsamında Havran barajının beslendiği havzanın belirlenmesi için bölgeye ait sayısal arazi modeli, NASA Shuttle Radar Topography Mission (SRTM v.3) veri kaynakları kullanılarak oluşturulmuştur (NASA, 2020). Havza için oluşturulan sayısal topografik harita üzerinden ortalama yüzey eğimleri ve yüzeysel akışın gerçekleştiği drenaj güzergâhları tespit edilmiştir. Havza, topoğrafik yapısına, jeolojik yapısına ve arazi kullanımına göre alt havzalara ayrılmıştır.

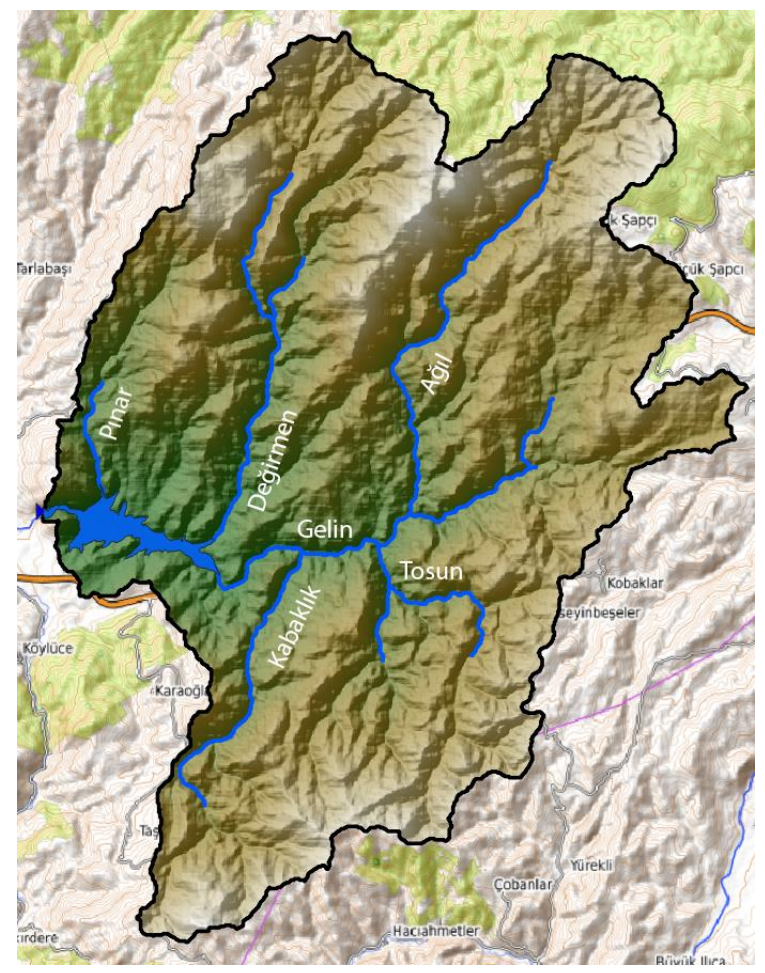

Şekil 2. Havran baraj gölü havzası

Alt-havzaların bulunduğu topografik konuma göre sayısal arazi modeli kullanılarak ortalama arazi eğimleri hesaplanmıştır. Althavzalarda tanımlanan arazi eğimleri dağılımı Şekil 3 ile gösterilmektedir.

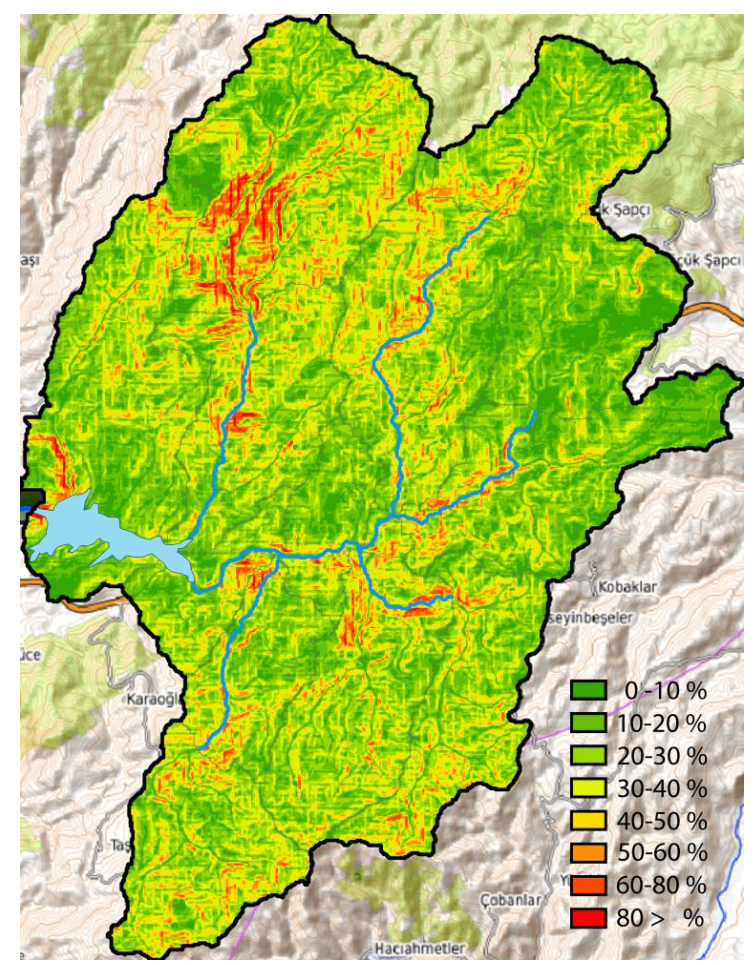

Şekil 3. Arazi Ĕğimleri Dă̆ılımı 


\subsection{Jeolojik Yapı}

Ağıl ve Gelin deresinin aktığı alt havza çoğunlukla andezit ve tüf türü kırıklı ve gevşek yapida kayaçlardan oluşmaktadır. Değirmen ve Pınar deresi alt havzasında, andezit ve tüf oluşumları yanı sıra, killi kireçtaşı, kumtaşı ve marn türü zeminlere rastlanılmaktadır. Kabaklık ve Tosun deresi alt havzasında yer yer dasit ve riyolit türü yapılar bulunmaktadır (MTA, 1989). Havzanın jeolojik haritası Şekil 4'de gösterilmektedir.

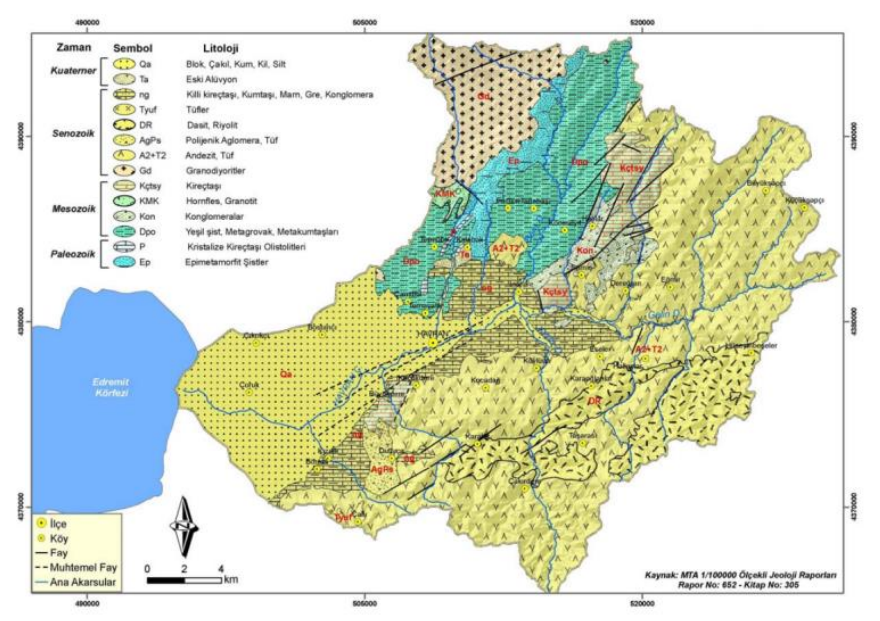

Şekil 4. Havzanin jeoloji haritası (MTA, 1989)

\subsection{Arazi Kullanım Türleri}

Yüzeysel deşarjların ve akarsuların havzalarını oluşturan alanların belirlenmesinde arazilerin güncel durumunu gösteren 2018 yılı CORINE sayısal haritaları kullanılmıştır (EEA, 2018). Alt havzalardaki arazi kullanım biçimleri Şekil 5.'de gösterilmektedir.

CORINE verileri kullanılarak yapılan çalışmaya göre Havran baraj gölüne ait 18.785,12 ha'lık havzada, ormanlık ve yarı doğal alanların toplamı 12.402,71 ha, tarım alanlarının toplamı 6.125,23ha, şehir yapıları ve maden sahalarının toplamı ise $257,18 \mathrm{ha}$ olarak hesaplanmıştır.

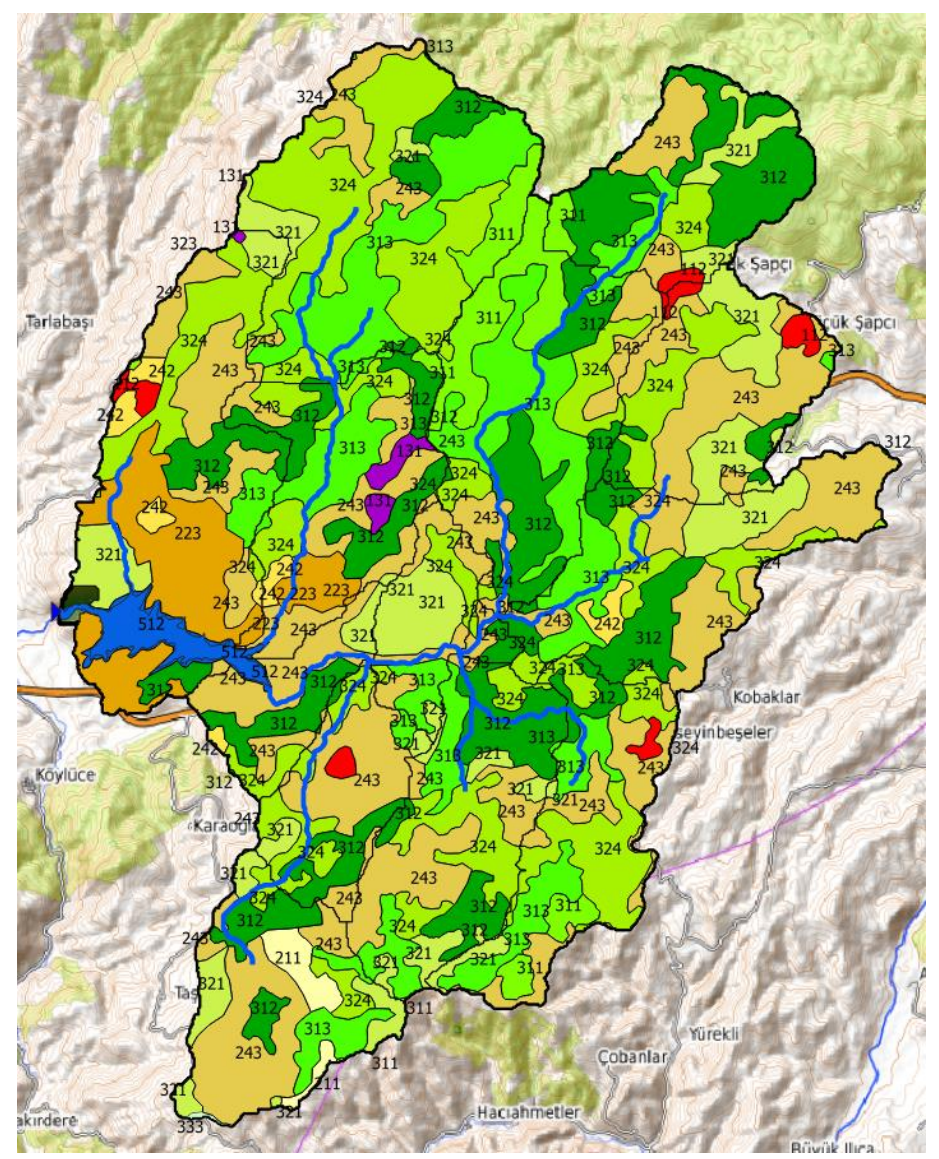

Şekil 5. Arazi kullanım haritası (EEA, 2018) 


\section{Avrupa Bilim ve Teknoloji Dergisi}

Doğal bitki örtüsü ile birlikte bulunan tarım alanları havzanın \%26,25'ini, bitki değişim alanları \%19,78'ini, iğne yapraklı ormanlar ise \%17,17'sini kapladığı görülmüştür. Havzadaki arazi kullanım türleri Tablo.1'de özetlenmiştir.

Tablo 1. Havzadaki arazi kullanım türleri (EEA, 2018)

\begin{tabular}{|l|c|c|c|c|}
\hline \multicolumn{1}{|c|}{ Düzey 3 } & $\begin{array}{c}\text { CORINE } \\
\text { kodu }\end{array}$ & $\begin{array}{c}\text { Alan } \\
\text { (ha) }\end{array}$ & $\begin{array}{c}\text { Yüzde } \\
\text { \% }\end{array}$ & $\begin{array}{c}\text { Sembol } \\
\text { rengi }\end{array}$ \\
\hline Kesikli şehir yapıs1 & 112 & 174,43 & 0,93 & \\
\hline Maden çıkarım sahaları & 131 & 82,74 & 0,44 & \\
\hline Sulanmayan ekilebilir araziler & 211 & 141,57 & 0,75 & \\
\hline Zeytinlikler & 223 & 859,94 & 4,58 & \\
\hline Karısıık tarım alanları & 242 & 193,51 & 1,03 & \\
\hline Doğal bitki örtüsü ile bulunan tarım alanları & 243 & 4930,21 & 26,25 & \\
\hline Geniş yapraklı ormanlar & 311 & 706,87 & 3,76 & \\
\hline İğne yapraklı ormanlar & 312 & 3224,76 & 17,17 & \\
\hline Karışık ağaç ormanları & 313 & 2748,17 & 14,63 & \\
\hline Doğal çayırlıklar & 321 & 1756,65 & 9,35 & \\
\hline Sklerofil bitki örtüsü & 323 & 0,47 & 0,00 & \\
\hline Bitki değişim alanları & 324 & 3715,75 & 19,78 & \\
\hline Seyrek bitki alanları & 333 & 3,85 & 0,02 & \\
\hline
\end{tabular}

\subsection{Meteorolojik Verilerin Derlenmesi}

Bölge yağış verileri Meteoroloji Genel Müdürlüğüne bağlı Burhaniye meteoroloji istasyonundan temin edilen veriler ile 5 yıllık ortalama yağış miktarları hesaplanmıştır.

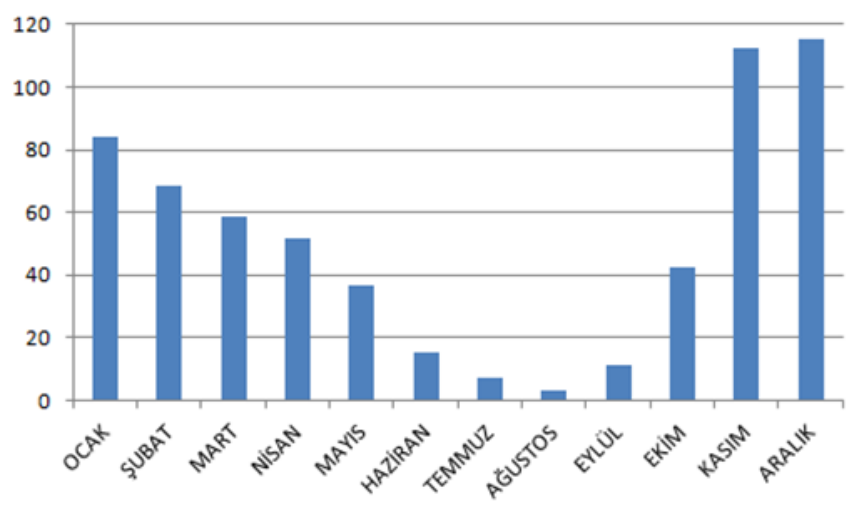

Şekil 6. Ortalama Aylık Yă̆̆ı̧ (mm)

Baraj gölü havzasının batısında bulunan Burhaniye istasyonundan elde edilen veriler ile bölgeye ait 5 yıllık ortalama sıcaklık ve buharlaşma miktarları hesaplanmıştır. Tablo 2'de aylık ortalama sıcaklık ve buharlaşma miktarları gösterilmektedir.

Tablo 2. Ortalama Sicaklık $\left({ }^{\circ} \mathrm{C}\right)$ ve Ortalama Buharlaşma ( $\left.\mathrm{mm}\right)$

\begin{tabular}{|c|c|c|c|c|c|c|c|c|c|c|c|c|}
\hline & Ocak & Şubat & Mart & Nisan & Mayıs & Haziran & Temmuz & Ağustos & Eylül & Ekim & Kasım & Aralık \\
\hline $\begin{array}{c}\text { Ort. } \\
\text { S1caklık }\end{array}$ & 6,8 & 6,9 & 9,4 & 14,5 & 17,8 & 24,2 & 27,5 & 26,7 & 22,8 & 16,5 & 11,4 & 8,6 \\
\hline $\begin{array}{c}\text { Ort. } \\
\text { Buharlaşma }\end{array}$ & - & - & - & 3,30 & 5,23 & 8,07 & 9,99 & 9,25 & 6,13 & 3,17 & 1,40 & 1,18 \\
\hline
\end{tabular}

\subsection{Akım Verileri}

Gelin deresi üzerinde Havran barajının bugün bulunduğu mevkide (27 11'25 ”D ve 39 34' 20”K), 1969 yılından 2003 yılında barajın inşasına kadar 408 nolu akarsu gözlem istasyonu (AGI) ölçüm yapmıştır. 408 nolu AGI'den elde edilen 30 yıllık akış debilerine ait aylık ortalama değerler Tablo 4'de verilmiştir. 
Tablo 3. Ayllk Ortalama Debi $\left(\mathrm{m}^{3} / \mathrm{s}\right)$

\begin{tabular}{|c|c|c|c|c|c|c|c|c|c|c|c|c|}
\hline & Ocak & Şubat & Mart & Nisan & Mayıs & Haziran & Temmuz & Ağustos & Eylül & Ekim & Kasım & Aralık \\
\hline $\begin{array}{c}\text { Aylık Ortalama } \\
\text { Debi }\left(\mathrm{m}^{3} / \mathrm{s}\right)\end{array}$ & 2,0459 & 2,4779 & 1,9946 & 1,3642 & 0,6179 & 0,2245 & 0,0102 & 0,0031 & 0,0040 & 0,0807 & 0,4768 & 1,9530 \\
\hline
\end{tabular}

\subsection{SWMM ile Yüzeysel Akışın Modellenmesi}

SWMM modeli ile yağışta yere düşen miktarın (yağmur suyu ve/ veya kar) sızma, buharlaşma gibi süreçlerden kalan miktarının yüzeysel akış ile drenajının hesabı yapılmaktadır. SWMM ile yağışın toplandığı havza birden fazla düzensiz şekilli alt-havzaya bölünebilmekte ve bu şekilde alt-havzalara farklı hidrolojik, hidrolik ve kullanım amacı atanabilmektedir.

SWMM yüzeysel akımın hesabı için doğrusal olmayan bir rezervuar modeli kullanır. Doğrusal olmayan rezervuar modeli tanımına göre alt-havzada yağış (yağmur, kar vb.) ile gelen su miktarında buharlaşma ve sızma ile kayıplardan sonra kalan miktarının göllenme oluşturduğu kabulü yapılmaktadır. Alt-havzada oluşan göllenmedeki suyun baskılanan depolama derinliği üzerinde kalan kısmı yüzeysel akışa geçmektedir.

Şekil 7'de görüldüğü gibi model, alt-havzayı uniform S eğimine sahip, W ortalama genişliğinde bir arazi olarak varsayarak, yüzeyde oluşan yüzeysel akışın bir drenaj havzasına aktarıldığı kabulleri ile hesap yapmaktadır.

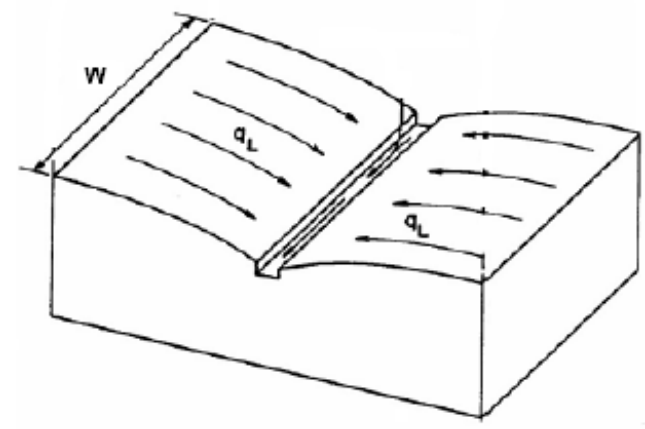

Şekil 7. İdeal Alt-Havza (Rossman, 2015)

Doğrusal olmayan rezervuar modeli (Şekil 8.) tanımına göre alt-havza yağı̧̧ (yağmur, kar ve diğ.) ile gelen su miktarında buharlaşma ve sızma ile kayıplardan sonra kalan miktarının d derinliğinde göllenme oluşturduğu kabulü yapılmaktadır. Alt-havzada oluşan göllenmedeki suyun baskılanan depolama derinliği $\left(\mathrm{d}_{\mathrm{s}}\right)$ üzerinde kalan kısmı yüzeysel akışa geçmektedir.

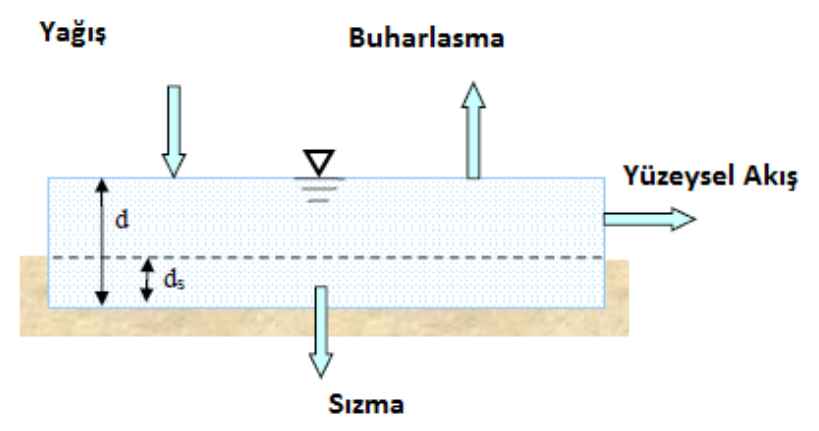

Şekil 8. Doğrusal Olmayan Alt-havza Rezervuar Modeli (Rossman, 2015)

Kütlenin korunumu denklemine göre $t$ zamanında $d$ derinliğindeki net değişim, alt-havzadaki girdilerin ve çıktıların arasındaki farka eşittir. Bu eşitlik ile ifade edilmektedir (Rossman, 2015).

$$
\frac{\partial d}{\partial t}=i-e-f-g
$$

Burada tüm değiş̧kenler birim alan için olmak üzere, i yağış hızı $(\mathrm{mm} / \mathrm{s})$, e yüzeysel buharlaşma hızı $(\mathrm{mm} / \mathrm{s})$, f sızma hızı $(\mathrm{mm} / \mathrm{s})$, q yüzeysel akış hızı $(\mathrm{mm} / \mathrm{s})$ 'dir. Alt-havza yüzeyindeki akışın, $\mathrm{W}$ genişliğinde ve $\mathrm{S}$ eğimine sahip dikdörtgen kesitli kanal içerisinde $\left(\mathrm{d}-\mathrm{d}_{\mathrm{s}}\right)$ yüksekliğindeki uniform bir akım gibi davrandığı varsayımı yapılmaktadır. Bu akıma ait debi Manning eşitliği ile aşağıdaki gibi hesaplanmaktadır.

$$
Q=\frac{1}{n} S^{1 / 2} R^{2 / 3} A_{x}
$$


Bu denklemde Q yüzeysel akış debisi ( $\left.\mathrm{m}^{3} / \mathrm{s}\right)$, S ortalama arazi eğimi $(\mathrm{m} / \mathrm{m})$, R hidrolik yarıçap $(\mathrm{m}), \mathrm{A}_{\mathrm{x}}$ kanal kesit alanıdır $\left(\mathrm{m}^{2}\right)$ ve $A x=W .\left(d-d_{s}\right)$ şeklinde ifade edilebilir. Birim alan için hesaplanan q debisi ise aşağıdaki eşitlikle gösterilebilir.

$$
q=\frac{w \cdot s^{1 / 2}}{A \cdot n}\left(d-d_{s}\right)^{5 / 3}
$$

Eşitlik kütlenin korunumu denkleminde yerine konulduğunda aşağıdaki hali almaktadır.

$$
\frac{\delta d}{\delta t}=i-e-f-\frac{w \cdot s^{1 / 2}}{A \cdot n}\left(d-d_{s}\right)^{5 / 3}
$$

Eşitlik (4) doğrusal olmayan bir diferansiyel eşitliktir ve bilinen i, e, f, ds, W, S, A ve n parametreleri için her zaman adımı için d derinliği sayısal olarak SWMM modeli içerisinde çözülmektedir (Rossman, 2015).

\subsection{Hidrolik ve Hidrolojik Parametreler}

Arazideki hidrolojik hesap birimleri, havzanın jeolojik yapısı, CORINE arazi kullanım türleri ve topografyaya göre belirlenmiştir. Hidrolojik hesap birimlerine ait hidrolik parametreler literatür araştırmalarına göre ortalama değerler olarak tespit edilmiştir. Tablo 4'de arazi kullanım türüne göre SWMM modelinde atanan geçirimsiz alan yüzdeleri bulunmaktadır.

Tablo 4. Arazi Kullanımına Göre Geçirimsiz Alanlar

\begin{tabular}{|l|l|l|l|l|l|l|}
\hline & $\begin{array}{l}\text { Geçirimsiz } \\
\text { alanların } \\
\text { yüzdesi (\%) } \\
\text { (USEPA, } \\
2014)\end{array}$ & $\begin{array}{l}\text { Depolama } \\
\text { olmayan } \\
\text { geçirimsiz } \\
\text { alanlar (\%) }\end{array}$ & $\begin{array}{l}\text { Geçirimsiz } \\
\text { alanların } \\
\text { Manning } \\
\text { katsayis1 } \\
\text { (Yen, 2001) }\end{array}$ & $\begin{array}{l}\text { Geçirimli } \\
\text { alanların } \\
\text { Manning } \\
\text { katsay1s1 } \\
\text { (Yen, 2001) }\end{array}$ & $\begin{array}{l}\text { Geçirimsiz } \\
\text { alanların } \\
\text { depolama } \\
\text { yüksekliği } \\
(\mathrm{mm})\end{array}$ & $\begin{array}{l}\text { Geçirimli } \\
\text { alanların } \\
\text { depolama } \\
\text { yüksekliği } \\
(\mathrm{mm})\end{array}$ \\
\hline Kesikli şehir yapıs1 & 51 & 25 & 0,030 & 0,075 & 1,27 & 2,54 \\
\hline Maden çıkarım sahaları & 10 & 25 & 0,030 & 0,032 & 1,27 \\
\hline Sulanmayan ekilebilir araziler & 2 & 10 & 0,030 & 0,12 & 1,27 \\
\hline Tarım alanları ve zeytinlikler & 2 & 10 & 0,030 & 0,055 & 1,27 \\
\hline Ormanlar ve bitki değişim alanları & 1,9 & 10 & 0,030 & 0,35 & 5,08 \\
\hline
\end{tabular}

Bölgede yüzeysel akışın gerçekleştiği drenaj güzergâhları topografik haritalar üzerinde tespit edilerek SWMM programında işlenmiş, GIS üzerinden yaklaşık uzunlukları belirlenerek kaydedilmiştir (Şekil 9.)

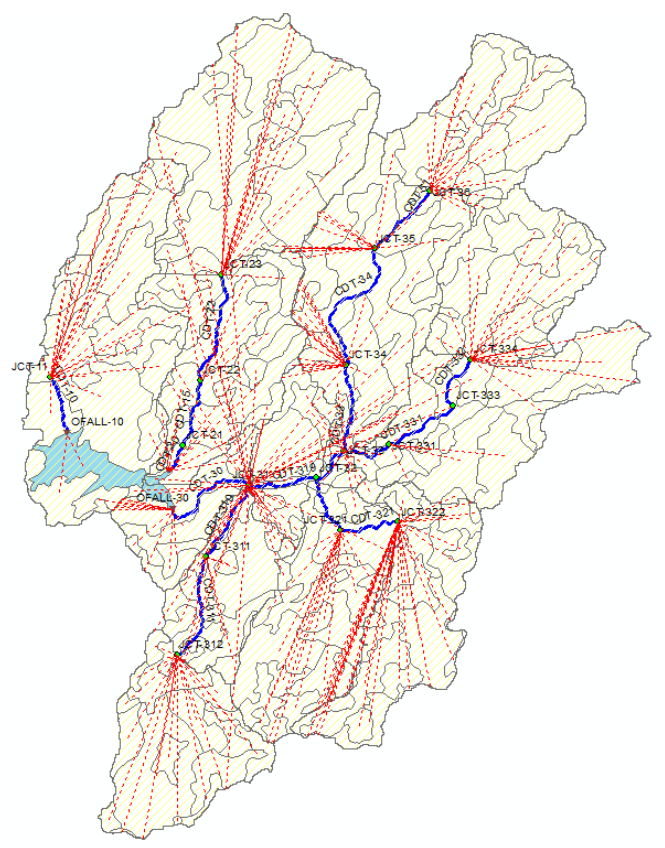

Şekil 9. Yüzeysel Akımların Toplanma Noktaları, Drenaj Güzergâhları ve Deşarj Noktaları

\section{Bulgular}

Havran baraj gölüne ait havza üzerinde SWMM modeli ile bir yıllık bir simülasyon yapıldığında yıl boyunca toplam 754,39mm yağış gerçekleştiği görülmüştür. Tüm havzada toplam yağışın $65.183,34 \mathrm{~m}^{3}$ 'lük kısmı ise yüzeysel akışa geçmektedir. 1, 2 ve 3 nolu Deşarj noktalarından baraj gölüne deşarj edilen yüzeysel akışların yıllık ortalama ve maksimum değerleri Tablo 5'de sunulmaktadır. 
European Journal of Science and Technology

Tablo 5. SWMM Modeli Yüzeysel Akışlar

\begin{tabular}{|c|c|c|}
\hline Deşarj Noktas1 & Maks. Debi $\left(\mathrm{m}^{3} / \mathrm{s}\right)$ & Ort. Debi $\left(\mathrm{m}^{3} / \mathrm{s}\right)$ \\
\hline 1 & 0,763 & 0,097 \\
\hline 2 & 1,485 & 0,202 \\
\hline 3 & 5,064 & 0,675 \\
\hline
\end{tabular}

Pınar deresinin göle döküldüğü Deşarj 1'de maksimum debi $0,763 \mathrm{~m}^{3}$, Değirmen deresinin deşarj noktası olan Deşarj 2'de 1,485 $\mathrm{m}^{3}$, en büyük alt havzayı içeren ve 3 adet kolu bulunan Gelin deresinin döküldüğü Deşarj 3 noktasında ise maksimum $5,064 \mathrm{~m}^{3}$ debi oluştuğu hesaplanmıştır. Yüzeysel akışların deşarj noktalarında hesaplanan debilere ait zaman grafiği Şekil 10'da sunulmaktadır.

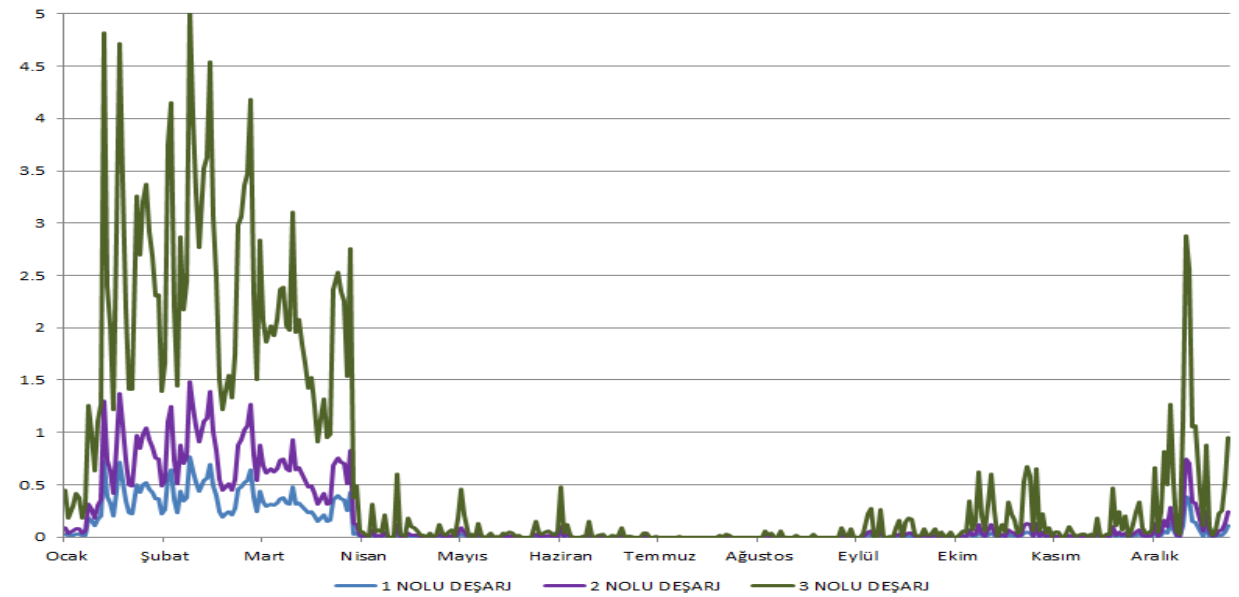

Şekil 10. 1, 2,3 Nolu Deşarj Noktalarındaki Deşarj Miktarları

Ortalama yağış verileri ile SWMM modeli aracılığıyla hazırlanan modele göre Havran baraj gölüne dökülen ortalama yüzeysel akış, AGI'nin 30 yıllık ortalama ölçüm değerleri ile Şekil 11'de kıyaslanmıştır.

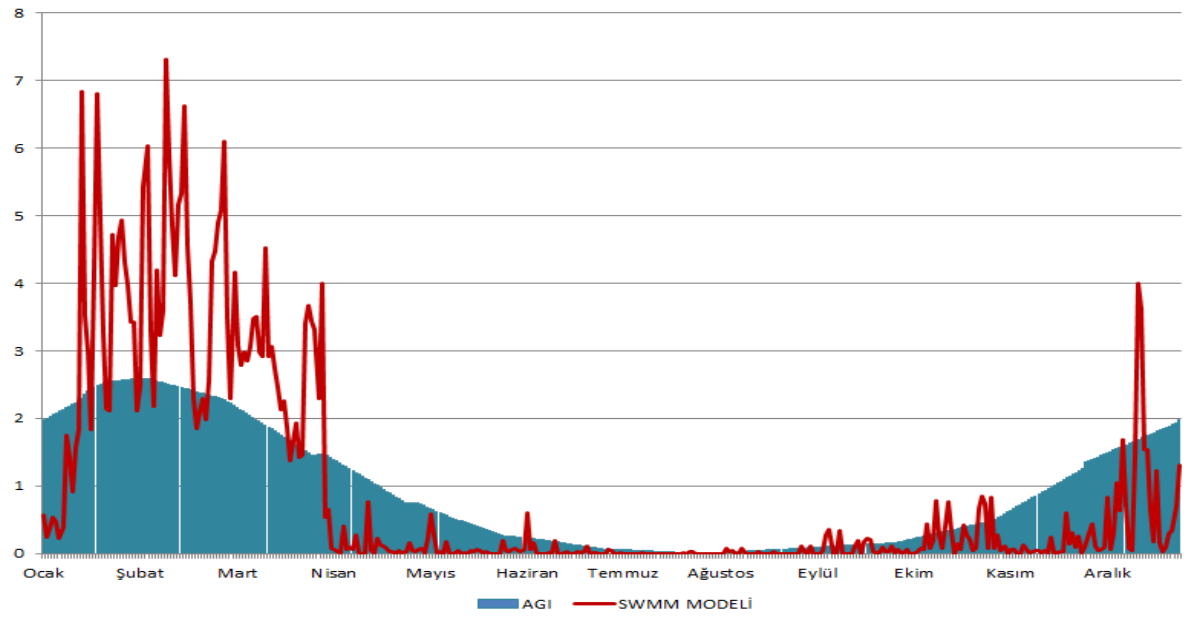

Şekil 11. Baraja Deşarj Edilen Toplam Yüzeysel Akış

\section{Sonuçlar}

Bu çalışmada Havran baraj gölüne ait havza SRTM sayısal yükseklik haritalarıyla belirlenmiş, yüzeysel akışları göle deşarj eden akarsulara ait güzergâhlar sayısal haritalara işlenmiştir. Bölgenin yağış, sıcaklık ve buharlaşma değerleri, Burhaniye meteoroloji istasyonundan temin edilen verilerin 5 yıllık ortalamaları alınarak elde edilmiştir. Baraj gölüne dökülen yüzeysel akış miktarının tespiti için havza, bölgenin topografik durumu, jeolojik yapısı ve arazi kullanım biçimlerine göre oluşturulan hidrolojik birimlere ayrılmıştır. SWMM yazılımı kullanılarak tüm havza için hidrolojik işlem birimleri tanımlanarak bir yıllık simülasyon yapılmıştır. Simülasyon sonucunda modelden hesaplanan yüzeysel akışlar, bölgede bulunan AGI verileri ile karşıllaştırılmış ve mevsimsel ortalama değerlere yakın olduğu tespit edilmiştir.

CBS yöntemleri kullanan SWMM gibi hidroloji ve taşkın yazılımları, geniş havzalarda yapılacak hidrolojik hesapların değerlendirilmesi açısından pratik bir araç sağlamaktadır. Bu tür modellemelerde ihtiyaç duyulan veriler bölgesel meteoroloji istasyonlarından sağlanabilmektedir. Alana ait hidrolik parametrelerin değerlendirilmesi açısından sayısal CORINE arazi kullanım haritalarından yararlanılmıştır. Arazi kullanım biçimlerine dayalı olarak hidrolojik değişkenlerin tanımlanması modelleme sırasında pratik bir yaklaşım sağlamaktadır. 


\section{Kaynakça}

ASCE, American Society of Civil Engineers. (1992). Design and Construction of Urban Stormwater Management Systems, New York, USA.

BÇŞİM, Balıkesir Çevre ve Şehircilik İl Müdürlüğü. (2020). Balıkesir İli 2018 Yılı Çevre Durum Raporu, Balıkesir Valiliği, Mayıs 2019. Erişim tarihi: 12 Şubat 2020, https://webdosya.csb.gov.tr/db/ced/icerikler/bal-kes-r_2018_-cdr_rev-ze-20190807131228.pdf

BİKTM, Balıkesir İl Kültür ve Turizm Müdürlüğü. (2020). Fiziki Özellikler, Erişim tarihi: 12 Şubat 2020. https://balikesir.ktb.gov.tr/TR-65836/fiziki-ozellikler.html.

Chen, C. L. (1982). "An evaluation of the mathematics and physical significance of the Soil Conservation Service curve number procedure for estimating runoff volume", Proc., Int. Symp. on Rainfall Runoff Modeling, Water Resources Publ., Littleton, Col., $387-418$.

Daniel, E. (2011). "Watershed Modeling and its Applications: A State-of-the-Art Review", The Open Hydrology Journal, 5: 26-50. DOI: $10.2174 / 1874378101105010026$.

EEA, European Environment Agency. (2018). Corine Land Cover 2018 (Version 20), Kopenhagen, Denmark.

Feldman, A.D. (1981). "HEC Models for Water Resources System Simulation: Theory and Experience", Advances in Hydroscience, ed. Chow, V. T., 12: 297-423, New York. DOI: 10.1016/B978-0-12-021812-7.50010-9

Googlemaps. (2020). [Online]. Available: https://www.google.com/maps/place/Havran+Baraj\%C4\%B1/@39.5747409,27.1703675,17z/data=!3m1!4b1!4m5!3m4!1s0x14b0 cad2b8e48bc3:0x737eb8483383274a! $8 \mathrm{~m} 2 ! 3 \mathrm{~d} 39.5747368 ! 4 \mathrm{~d} 27.1725562$

MTA, Maden Tetkik ve Arama Genel Müdürlüğü. (1989). 1:100000 Ölçekli Açınsama Nitelikli Türkiye Jeoloji Haritaları Serisi, Ayvalık - G3 Paftasl, Maden Tetkik ve Arama Genel Müdürlüğü, Ankara.

NASA. (2020). The Shuttle Radar Topography Mission (SRTM) Collection User Guide, Available: https://lpdaac.usgs.gov/documents/13/SRTM_Quick_Guide.pdf

Nelson, E.J., Jones, N.L., and Miller, A.W. (1994). “An algorithm for precise drainage basin delineation”, ASCE Journal of Hydraulic Engineering, 120 (3): 298-312.

Özdemir, H. and Bird, D. (2009). "Evaluation of Morphometric Parameters of Drainage Networks Derived from Topographic Maps and DEM in Point of Floods", Environmental Geology, 56: 1405-1415. DOI: 10.1007/s00254-008-1235-y

Rossman, L. A. (2015). Stormwater Management Model Reference Manual, Volume-I Hydrology, USEPA, EPA/600/R-15/162.

SCS, Soil Conservation Service. (1986). Urban Hydrology for Small Watersheds, Tech., rel.55, Washington, DC, USA.

USEPA, United States Environmental Protection Agency. (2014). Estimating Change in Impervious Area (IA) and Directly Connected Impervious Areas (DCIA) for New Hampshire Small MS4 Permit. Small MS4 Permit Technical Support Document, USEPA Region I, Boston, MA, USA. Available:http://www.epa.gov/region1/npdes/stormwater/nh/NHDCIA.pdf

USEPA, United States Environmental Protection Agency. (2019). BASINS 4.5 (Better Assessment Science Integrating point \& Nonpoint Sources) Modeling Framework, National Exposure Research Laboratory, RTP, North Carolina.

Yen, B.C. (2001). "Hydraulics of Sewer Systems”, Chapter 6 in Stormwater Collection Systems Design Handbook, L.M. Mays, ed., McGraw-Hill, New York, USA. 